\title{
An in vitro assay for neural crest cell migration through the somites
}

\author{
GEORGIA GUILLORY AND MARIANNE BRONNER-FRASER \\ Developmental Biology Center and Department of Developmental and Cell Biology, \\ University of California, Irvine, California 92717, USA
}

\begin{abstract}
SUMMARY
Neural crest cells in the trunk of the avian embryo come into contact with the somites and neural tube during the course of their migration. However, the relationship between the somites and the early migratory routes followed by these cells is not yet completely understood. Here, we use a tissue culture assay to examine if avian neural crest cells migrate through the somites. Cultures of quail somites were prepared from four adjacent regions along the neural axis in the trunk. Each region had four pairs of consecutive somites with region I being most anterior and region IV containing the last four segments. Within each region, the somites were separated from other tissues by enzymatic digestion and plated onto collagen-coated dishes. Immunocytochemical techniques were used to confirm that no neural crest cells, recognized by the HNK-1 antibody, were present on the surface of the somites at the time of explantation. After several days in culture, the explanted somites were screened to identify pigment cells. Because neural crest cells give rise to all of the melanocytes in the trunk, the presence of pigment cells indicated that neural crest precursors were contained within the initial explant. After 5-11 days in vitro, the percentage of somite cultures containing pigment cells in regions I through IV, respectively, was $36 \%, 51 \%, 31 \%$ and $1 \%$. These results suggest that neural crest cells migrate through the somitic mesenchyme and first enter the somites between 5 to 9 segments rostral to the most recently formed somite.
\end{abstract}

\section{INTRODUCTION}

The neural crest is a migratory cell population that originates in the dorsal neural folds and initiates migration shortly after closure of the neural tube. Neural crest cells first begin migrating in the cranial region, with the wave of crest cell migration occurring in an anteroposterior direction along the neural axis. During their migration, neural crest cells come into contact with the neural tube and the somites. In the trunk region of the embryo, neural crest cells have classically been thought to follow two primary migratory pathways: (1) a dorsolateral pathway, under the ectoderm and (2) a ventral pathway, between the neural tube and the somites. Those cells that migrate dorsolaterally differentiate into pigment cells, while those neural crest cells that migrate ventrally differentiate into numerous cell types including sensory and autonomic ganglia, glial and Schwann cells, and chromaffin cells.

Key words: neural crest, migration, somites, pigment cells, in vitro, quail, Coturnix coturnix japonica. 
Because of the difficulties in distinguishing morphologically undifferentiated neural crest cells from the tissues through which they move, details concerning the exact migratory pathways of these cells are not yet fully understood. In early studies on Ambystoma embryos, Detwiler (1937) reported that the neural crest gives rise to spinal and sympathetic ganglia, and observed a direct correlation between the number of somites and dorsal root ganglia (Detwiler, 1934). When additional somites were grafted into the embryo, a corresponding increase in dorsal root ganglia number was found; when somites were deleted, fewer dorsal root ganglia, corresponding to the number of somites deleted, were observed. In avian embryos, Weston (1963) also noted a relationship between somites and neural crest cells. Using $\left[{ }^{3} \mathrm{H}\right]$ thymidine-labelled neural crest cells, he reported that the migration of neural crest was enhanced within the somitic mesenchyme, while migration between the somites was limited. Based on these results, Weston concluded that neural crest migration is facilitated when cells move through an organized cellular environment, such as the somitic mesenchyme. In a related study using quail-chick chimaerae and antibodies to fibronectin, Thiery, Duband \& Delouvee (1982) examined the relationship between neural crest cells and the distribution of fibronectin (FN) during the early stages of neural crest migration. They concluded that neural crest cells migrate along FN-rich pathways and that the cells move predominantly between the neural tube and somites, or between adjacent somites through a narrow, acellular space. It was suggested that those neural crest cells in the intersomitic space migrate rapidly because no physical barriers prohibit their ventral movement. In contrast, those cells that move between the neural tube and somite were proposed to be trapped between the expanding sclerotome and neural tube where they form the dorsal root ganglia.

The studies described above suggest different possible roles for the somites in the migration of neural crest cells within the developing embryo. The somites are formed from the segmental plate mesoderm which prior to segmentation, consists of flat, loosely arranged mesenchymal cells (Bellairs, 1979). Segmentation occurs in a dorsal-to-ventral fashion as cells on the dorsal surface become more elongated and covered with fibrillar extracellular material, that is probably collagenous (Bellairs, 1979; Bellairs \& Veini, 1980). The newly formed somite comprises elongated, spindle-shaped epithelial cells arranged radially around a lumen, the myocoele. The somite becomes enclosed within collagenous fibrils which attach to the neural tube, notochord, ectoderm, and endoderm, thus stabilizing the form of the somite. As development proceeds, the epithelial somite breaks up into three cell layers: (1) the dermatome, (2) myotome, and (3) sclerotome. The dermatome contributes to the formation of the connective tissue layer of the skin, the myotome contributes to somatic muscle, and the sclerotome contributes to the formation of the cartilage surrounding the notochord and spinal cord.

The present experiments were designed to further explore the relationship between the somites and migrating neural crest cells. In particular, we addressed the discrepancy between the experiments of Weston (1963), who proposed that neural crest cells migrate through the somite, and those of Thiery et al. (1982) who 


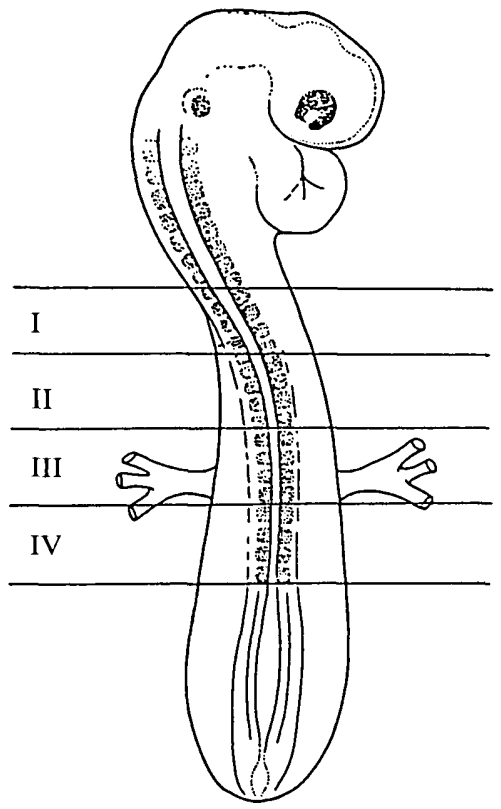

Fig. 1. Schematic diagram illustrating the regions along the neural axis from which the somites were derived. The neural axis was divided into four adjacent regions, each containing four pairs of consecutive somites. Region I contained the most anterior somites used in this study and, depending on the exact stage of the embryo, extended caudad from somite no. 5 to no. 11. Immediately caudad to region I was region II, followed by region III. Region IV, the most caudal region, contained the four most recently formed somites.

suggested that neural crest cells migrate around the somite. In this study, individual somites from adjacent regions along the neural axis were placed in culture in the absence of other tissue. After several days in vitro, the appearance of neural-crest-derived pigment cells in cultures of somites was used as an assay for neural crest precursors within the initial explant.

\section{MATERIALS AND METHODS}

\section{Preparation of somite cultures}

Somite cultures were prepared using quail embryos (Coturnix coturnix japonica) that were incubated for $48 \mathrm{~h}$ at $38^{\circ} \mathrm{C}$, at which time their developmental age was comparable to Hamburger \& Hamilton (1951) stage 13-15 (containing, 19 and 24-27 somites, respectively). The neural axis was divided into four adjacent regions (Fig. 1), each containing four pairs of consecutive somites; these regions were labelled I to IV, with region IV containing the most recently segmented somites. Using a tungsten needle, tissue from each region was removed from the embryo, isolated from the other regions, and placed into Pancreatin (Gibco; $0.6 \%$ in Howard Ringers saline solution) for 20-25 min on ice or collagenase (Cooper Biomedical; CLS type II, $1 \mathrm{mg} \mathrm{ml}^{-1}$ in Howard Ringers saline solution) for $15 \mathrm{~min}$ on ice followed by a $9 \mathrm{~min}$ incubation at $37^{\circ} \mathrm{C}$. Both enzymatic treatments yielded similar results which are presented collectively. The somites were gently pipetted loose from the surrounding tissue, rinsed twice in Howard Ringers, and rinsed once in culture medium consisting of $10 \%$ chick embryo extract, $15 \%$ horse serum and Eagle's minimum essential medium (MEM, Gibco). Individual somites 
were plated in 24-well multiwell plates coated with rat tail collagen. The somites were fed 3-4 h after plating and then every other day; somite cultures were observed daily and maintained for 12-13 days. A pigmentation index for each region was determined by counting the number of wells that contained pigment cells and comparing this to the total number of wells for that region (\% of wells with pigment cells in them).

\section{Preparation of neural tube cultures}

To compare the timing of pigmentation in neural crest cells arising from neural tube versus somite cultures, neural tubes from regions I to IV were isolated as described above and cultured for 12-13 days. Neural tube cultures were observed daily for the presence of pigment cells.

\section{Immunocytochemistry using the monoclonal antibody $H N K-1$}

Somites and neural tubes from region III were dissected from the embryo as described above. After enzymic treatment with pancreatin or collagenase, the explants were rinsed three times in Howard Ringers solution and once in MEM. They were then placed into fresh MEM and allowed to recover for $1-2 \mathrm{~h}$ at $37^{\circ} \mathrm{C}$. Neural tube explants were plated onto fibronectin-coated dishes preincubated with tissue culture medium. After $2-3 \mathrm{~h}$, some neural crest cells migrated onto the substratum.

After a total of $2-4 \mathrm{~h}$ in vitro, the somites or neural tube explants were rinsed three times in Howard Ringers saline and subsequently fixed in methanol overnight at $4^{\circ} \mathrm{C}$. The fixed explants were rinsed and incubated for $3 \mathrm{~h}$ at room temperature in culture medium supernatant from HNK-1 hybridoma cells. This was followed by a $1 \mathrm{~h}$ incubation with rabbit antibodies against mouse IgMs (1:25) and finally $1 \mathrm{~h}$ with fluorescein-conjugated goat antibodies against rabbit IgGs $(1: 25)$. Sheep antibodies against guinea pig IgGs were added to reduce the nonspecific staining. The tissues were examined through a Zeiss microscope equipped with epifluorescence using a filter set designed for fluorescein.

\section{Catecholamine histofluorescence}

Formaldehyde-induced-fluorescence (FIF) was performed on cultures to assay for catecholamine-containing cells within the somitic tissue. The culture medium was removed, the plates were air dried, and exposed to paraformaldehyde vapours for $1 \mathrm{~h}$ at $80^{\circ} \mathrm{C}$. The cultures were observed on a Zeiss universal microscope equipped for epifluorescence, using a BP $405 / 6$ excitation and a LP 435 barrier filter. Catecholamines fluoresce with a characteristic excitation/ emission of 420 and $480 \mathrm{~nm}$, respectively.

\section{Scanning electron microscopy}

For scanning electron microscopy, somites were dissected following the protocol described above. After dissociation, they were allowed to recover in Eagle's minimum essential medium (MEM, Gibco) for 1 to $1.5 \mathrm{~h}$, stained with neutral red for $3 \mathrm{~min}$, then fixed in $4 \%$ glutaraldehyde in $0.1 \mathrm{M}$-phosphate buffer saline, $\mathrm{pH} 7 \cdot 4$, for $3 \mathrm{~h}$ on coverslips coated with poly-l-lysine or 20-25 $\mu \mathrm{m}$ metal grids (Tetko, Inc.). The tissue was rinsed and postfixed in $1 \%$ osmium

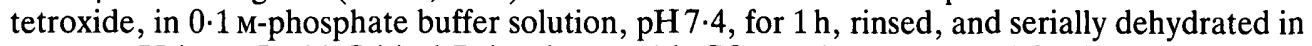
acetone. Using a Ladd Critical Point dryer, with $\mathrm{CO}_{2}$ as the transitional fluid, the tissue was dried at a critical pressure and temperature of $7397 \mathrm{kPa}$ and $31^{\circ} \mathrm{C}$, respectively. All samples were sputter coated with gold for 3 min using a Technics Hummer II ionizing sputter coater prior to observation on a Hitachi S-500 scanning electron microscope.

\section{RESULTS}

Individual somites were removed from regions I through IV (see Fig. 1), placed into multiwell plates, and cultured under conditions that promote the differentiation of neural crest cells into melanocytes and adrenergic cells (Cohen, 1977). 

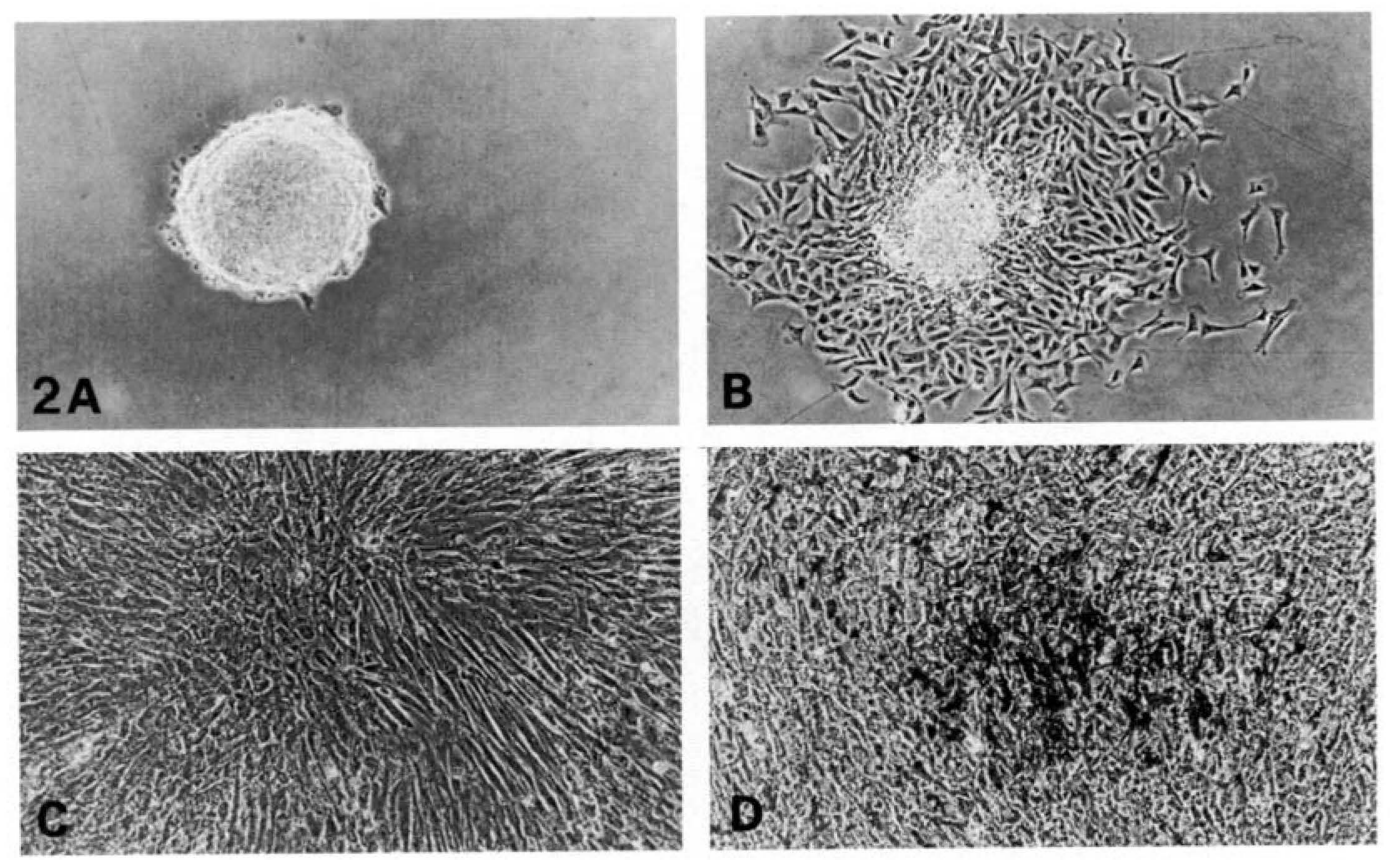

Fig. 2. Phase contrast photomicrographs of somite cultures explanted from region II. (A) After initial explantation, the somite appears spherical in shape. (B) By $24 \mathrm{~h}$ in culture, most cells have left the explant, flattened onto the dish, and formed a symmetrical array around a central aggregate. (C) After 4 days in culture, the cells have proliferated extensively and spread in all directions away from the initial explant. The somite cells often appeared aligned in a striated fashion. (D) A somite culture 8 days after explantation, in which many neural crest cells have differentiated into pigment cells identified by their dark melanin granule. In this somite, the pigment cells were randomly distributed among the somite cells. $\times 100$.

The differentiation of neural-crest-derived pigment cells, identified by dark melanin granules in their cytoplasm, served as a convenient and unique marker for presence of neural crest cells within the initial explant.

During the first 1-4 days in vitro, somite cultures from regions I-IV exhibited many of the same morphological characteristics. The initial structure of somites was spherical, and this shape was retained throughout dissection and enzymic digestion of the tissue (Fig. 2A). Along the rostrocaudal axis, the size of the freshly dissected somites progressively decreased. After $24 \mathrm{~h}$ in culture, somites from all regions lost their spherical structure as the somitic tissue became more flattened onto the substratum; the somitic cells then dispersed to form a symmetrical array of flattened cells around a central aggregate (Fig. 2B). By 2 days in culture, the cells divided rapidly and spread in all directions away from the initial explant. The cell population increased in each well and the cells generally formed a whorled pattern (Fig. 2C).

Somite cells from regions I, II and III typically survived well when grown under conditions that promote the differentiation of neural crest into melanocytes and 
adrenergic cells. Pigment cells appeared in some of the somite cultures between 5 to 11 days after explantation. After pigment expression, both the pigment and somite cells coexisted and proliferated. As the number of melanocytes in each well increased, the somite cells and melanocytes were observed in one of the following configurations: (1) the pigment cells became aligned along the muscle fibres, (2) clusters of pigment cells became buried within a mass of nonpigmented cells, or (3) individual pigment cells were randomly distributed among the somite cells (Fig. 2D). In a few cases, some somite cells from region I, II or III became vacuolated and excessively flattened, characteristics of dying cells. In many of these cultures, neural crest cells still differentiated into pigment cells after day $5-11$; in fact, pigment cells in the wells containing dying somite cells continued to proliferate and eventually became the predominate cell type in the culture.

In general, somites from region IV (the most recently formed somites) differed from those of regions I through III. After 4-5 days in culture, most somite cells began to develop vacuoles and flatten extensively onto the substrate; this condition became progressively worse, until many cells died and the total number of cells in each well was small.

\section{Region I}

Somites were explanted from hosts ranging in age from stage 13 to 15 (Hamburger \& Hamilton, 1951); therefore, the explants we call region I extended caudad from somite no. 5 to no. 11. A total of 39 somites from this region were plated, 14 of which developed pigment after 5 to 11 days in culture. The pigmentation index was determined by counting the number of wells containing pigment cells and comparing this to the total number of wells per region. For region I, the pigmentation index was $36 \%$. All wells were exposed to formaldehyde-induced fluorescence (FIF), and 5 of the 39 cultures contained some cells with weak catecholamine histofluorescence; these same wells also contained pigment cells (Table 1).

Table 1. A summary of the results from all experiments

\begin{tabular}{lcccc}
\hline & \multicolumn{4}{c}{ Region along the neural axis } \\
\cline { 2 - 5 } & I & II & III & IV \\
\hline $\begin{array}{c}\text { Total somites } \\
\text { explanted } \\
\text { Total somites } \\
\text { expressing pigmentation }\end{array}$ & 14 & 59 & 33 & 1 \\
$\begin{array}{c}\text { Pigmentation } \\
\text { index (\%) } \\
\text { Total somites } \\
\text { with catecholamine } \\
\text { histofluorescence }\end{array}$ & 36 & 51 & 38 & 1 \\
\hline
\end{tabular}

Somites were explanted from regions I-IV. The number of somites containing pigmented and adrenergic cells was determined. The pigmentation index was calculated as the percentage of somites containing pigment relative to the total number of somites explanted for that region. 


\section{Region II}

As in region $I$, the staging of the embryo varied between stage 13 to 15 ; therefore, in region II the most rostral somites ranged from somite no. 9 to no. 15 . Of the 115 wells containing individual somites, pigment cell differentiation was observed in 59 of the wells and was detected between day 5 to 11 in culture (Fig. 3A,B). The pigmentation index for region II was $51 \%$. All somite explants were exposed to FIF in order to check for catecholamine-containing cells. 24 of the 115 wells also had cells containing weak catecholamine histofluorescence. These same wells also contained pigment cells (Table 1).

\section{Region III}

The most rostral somite number for explants from region III ranged from no. 13 to no. 19. A total of 86 somites was plated; pigment cells developed in 33 of these wells and were first detected between 7 and 10 days in vitro. The pigmentation index for this region was $38 \%$. To assay for the presence of catecholaminecontaining cells, all wells were tested for FIF. Weak histofluorescence was observed in some cells within 21 wells; these wells also contained pigment cells (Table 1).

\section{Region IV}

Region IV was located most caudally along the neural axis and contained the four most recently formed somites. The most rostral somite ranged from somite no. 17 to no. 21 . A total of 88 somites was explanted from this region (Fig. 3C); pigment cells differentiated in only one of the wells and were first observed on day 9 in culture. The pigmentation index for region IV was $1 \%$. All of the somites were exposed to FIF in order to check for the presence of catecholaminergic cells. The same well that contained pigments cells also had cells with weak catecholamine histofluorescence (Table 1).

\section{Neural tube cultures}

To test if the dissection and enzymic digestion of the somites from the surrounding tissue interfered with the normal differentiation of neural crest cells into melanocytes, neural tubes from regions I to IV were plated and observed in culture for the presence of pigment cells. Pigment cells developed in neural tube cultures from all regions after 7 to 10 days. This is in contrast to the somites, where only explants from region I, II and III contained pigment cells.

\section{Immunocytochemical detection of neural crest cells with HNK-1}

The HNK-1 antibody recognizes a carbohydrate moiety on the surface of migrating neural crest cells (Tucker et al. 1984). Previous investigators have shown that NC-1, which recognizes the same epitope, stains all neural crest cells in vitro 
(Vincent \& Thiery, 1984). We have used the HNK-1 antibody to examine the surface of explanted somites for the possible presence of adhering neural crest cells.
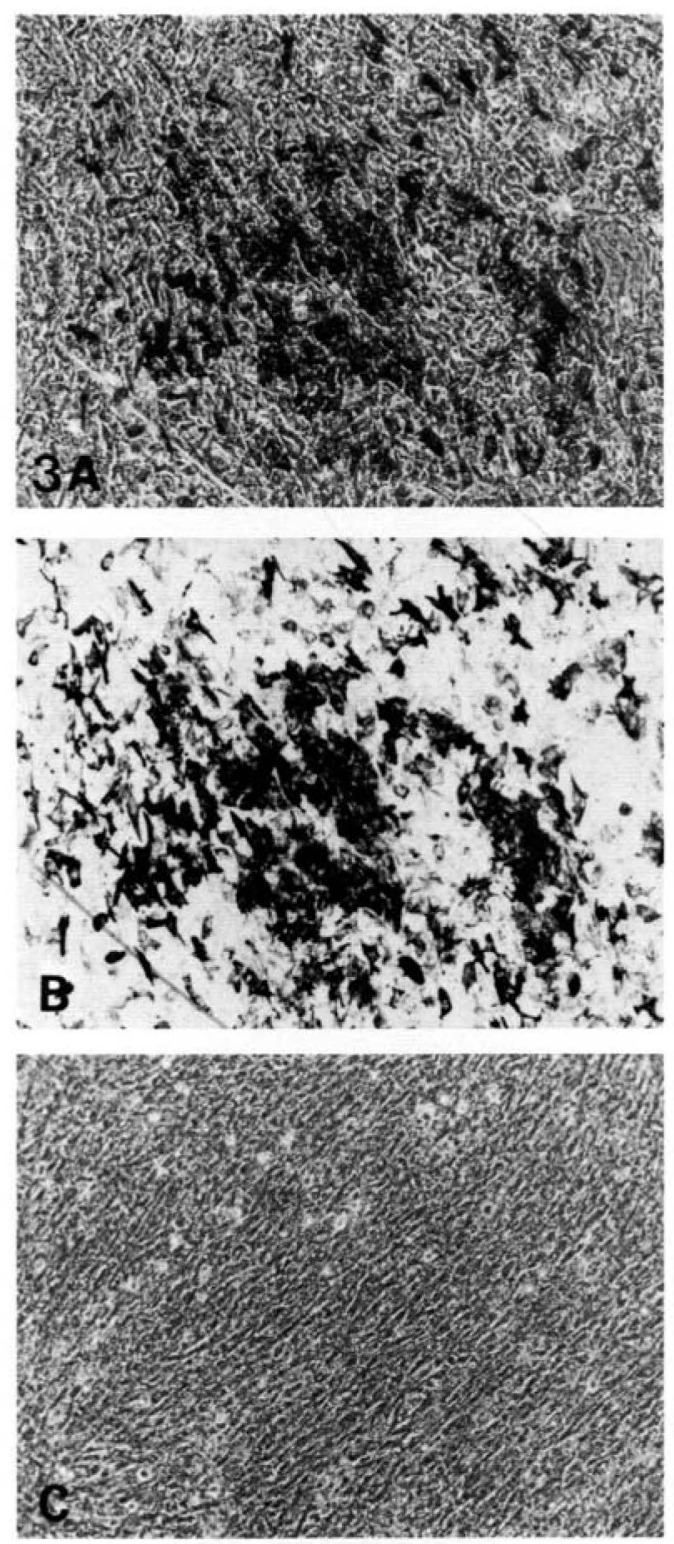

Fig. 3. Phase and bright field photomicrographs of 11 day somite cultures. (A) Phase contrast image of a somite explanted from region II. Numerous pigment, with dark melanin granules in their cytoplasm, were present within the mass of somite cells. The pigment cells are more visible in (B) which is a bright field image of the same field illustrated in (A). In contrast, (C) shows a phase contrast image of a somite explanted from region IV. There were no pigment cells within this somite or for the majority of explants from this region. $\times 100$. 

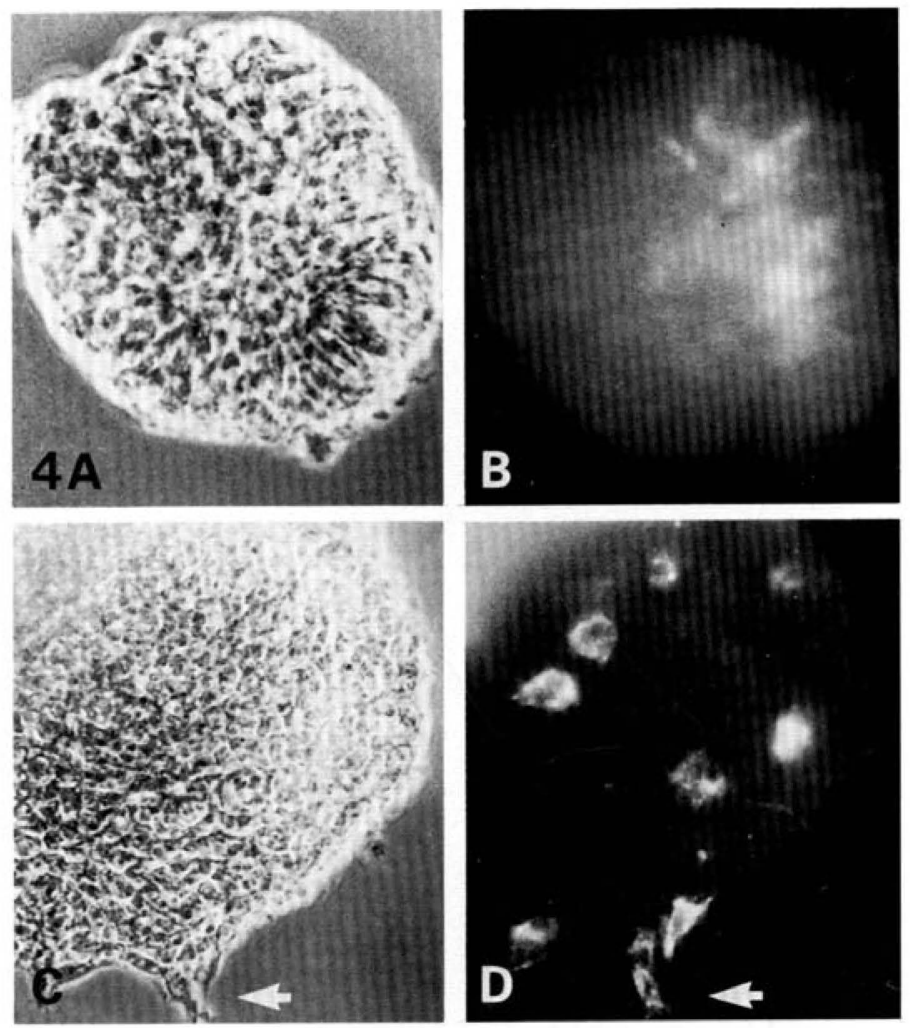

Fig. 4. Phase contrast $(A, C)$ and fluorescence $(B, D)$ photomicrographs of somites or neural tube explants stained with the HNK-1 antibody. (A) A somite from region III a few hours after explantation viewed with phase contrast optics. The image is focused on the somite surface. (B) The same somite viewed through a fluorescein filter set. No HNK-1 staining was observed on the somite surface, indicating an absence of contaminating neural crest cells at the time of explantation. Some HNK-1 immunoreactivity was, however, seen within the somite. (C) A neural tube explant prepared in the same manner as the somite described in (A) and (B). A few neural crest cells, identified by their HNK-1 staining, have emerged from the neural tube (as indicated by the arrow) and others can be seen on the surface of the tube. $\times 400$.

To confirm that HNK-1 does recognize neural crest cells under our staining conditions, somites and neural tubes from region III were prepared simultaneously and the neural crest cells emerging from the explanted neural tubes served as a positive control. In the neural tube cultures, neural crest cells stained intensely with the HNK-1 antibody after they had migrated away from the neural tube (Fig. 4C,D).

A total of 24 somites and 9 neural tubes were examined. In all neural tube cultures, neural crest cells on the tissue culture dish were stained with HNK-1. In contrast, no neural crest cells were observed on the surface of the somites prepared in the same manner (Fig. 4A,B). In some cases, however, it was possible to observe HNK-1-positive cells within the interior of the somite if one focused a few cell diameters below the somite surface. This suggests that HNK-1 antibodies 
penetrate within the fixed somites and confirm our observations that freshly explanted somites contain neural crest cells.

\section{Scanning electron microscopy}

Scanning electron microscopy (SEM) was used as further confirmation for the absence of adhering neural crest cells on the surface of the somites. Somites from regions II and III were enzymically digested from the surrounding tissue, fixed, dehydrated, critical-point dried, and sputter coated with gold. On many occasions the morphology of the somite was drastically changed as the somite became partially collapsed or shrunk. A few somites retained a spherical shape after SEM preparation and allowed for good visualization of the somite surface. 17 somites were examined in detail in the SEM. In no cases were neural crest cells, identifiable by their fibroblast-like morphology and the characteristic pseudopods of migratory cells (Tosney, 1978), observed on the surface of the somite. In contrast, it was possible to distinguish individual somite cells by their characteristic columnar morphology within the somitic epithelium.

\section{DISCUSSION}

This study was designed to examine the relationship between the somitic mesenchyme and the early migration of neural crest cells. Specifically, we addressed the following questions: (1) do neural crest cells pass through the somites during their ventral migration? and (2) if so, at what stage after neural tube closure and somite formation do the neural crest cells first invade the somites? An in vitro assay was used to establish the presence of neural crest cells within the somites. Individual somites from four consecutive regions (I-IV) along the rostrocaudal axis were cultured under conditions that are permissive for neural crest differentiation into pigmented and adrenergic cells. The differentiation of pigment cells indicates that neural crest precursors were initially present in the explant.

A significant percentage of somite explants from regions I, II and III, the three most anterior explants, contained pigment cells and adrenergic cells. The pigmentation index (PI) was $36 \%, 51 \%, 38 \%$ and $1 \%$, for regions I through IV, respectively. Because somites from region IV did not contain significant numbers of neural crest derivatives, the results suggest that neural crest cells have not yet invaded these somites in the majority of embryos at the time of explantation. Our findings suggest that neural crest cells pass through the somites during the early stages of their migration, and first enter into the somitic tissue in region III, i.e. approximately 5-9 somites rostral to the most recently formed somite. At this level, some of the somites have begun to laminate into the dermatome, myotome and sclerotome. Thus, the penetration of neural crest cells into the somites appears to correspond to the time of somitic dissociation.

The pigmentation index never reached $100 \%$ for any of the regions examined. Several possible explanations may account for this. For example, the neural crest 
precursors in some of the somites may not differentiate into pigment cells or may die. Alternatively, the enzymic digestions used in this study may remove many neural crest cells from within the loosely organized sclerotomal portion of the somite (Bronner-Fraser, 1986) in explants derived from more mature regions such as regions I and II. In addition, some recently formed somites may contain no neural crest cells. We are currently using monoclonal antibodies against neural crest cells to distinguish between these possibilities.

In the developing embryo, neurulation begins rostrally and progresses caudally. After neural tube closure, neural crest cells initiate migration from the newly formed neural tube; thus initiation of neural crest migration also occurs in a rostral-to-caudal wave. The pigmentation indices for regions I through IV, used as an assay for the initial presence of neural crest cells within the sclerotome, may reflect the extent of neural crest cell migration from the neural tube into the somite as a function of position along the neural axis. One possibility is that in region I $(\mathrm{PI}=36 \%)$, the oldest region with respect to neural tube closure, neural crest cells have been actively migrating, and many of the cells may have already passed through the sclerotome. In addition, the sclerotome in this region may be more dissociated than in more posterior regions and may, therefore, be lost during isolation of the somites. In region II $(\mathrm{PI}=51 \%)$, the somites consist of three layers: the dermatome, myotome and sclerotome. Region II has the highest pigmentation index found within explanted somitic tissue, which may reflect that neural crest cells are avidly migrating through the somite at this level of the neural axis. Region III (PI = 38\%) is the most caudal level where a significant percentage of somites contain neural crest cells. At this level of the neural axis, somites are just beginning to dissociate into the dermatome, myotome and sclerotome. This suggests that the first neural crest cells begin to enter the somites at the level when they first dissociate. In region IV $(\mathrm{PI}=1 \%)$, neural crest migration is just starting, the somites are epithelial in nature, and it appears that no neural crest cells have yet entered the somites in the majority of embryos.

The data obtained in our study support the conclusions of Weston (1963). In his autoradiographic analysis of the migration of thymidine-labelled neural crest cells, Weston (1963) suggested that neural crest cells following the ventral pathway migrated preferentially through the somite. Further experiments (Weston, 1963) also indicated that motor nerve fibres emerging from the ventral portion of the neural tube were encased by labelled cells, presumably Schwann cells, that had moved into the somitic mesenchyme.

Weston's findings were challenged in a recent study by Thiery et al. (1982). In experiments utilizing antibodies to fibronectin together with quail-chick chimaeric transplants, they reported that neural crest cells do not invade the somites but migrate preferentially between the neural tube and somites or between adjacent somites, along pathways rich in fibronectin. After the somite laminates into the dermatome, myotome and sclerotome, they proposed that the ventromedial expansion of the sclerotome 'trapped' the neural crest cells between the neural tube and sclerotome, where they form the dorsal root ganglia. They suggested that 
neural crest migration was more extensive in the intersomitic cleft due to the presence of a large acellular space, which was rich in fibronectin. In quail-chick chimaerae, they observed that neural crest cells found in the intersomitic space were widely dispersed along the ventral pathway and that these cells rapidly reached the notochordal region. In contrast, intrasomitically located crest cells remained condensed and were prevented from migrating due to the physical barrier created by the somitic sclerotome. Though the reasons for the contradictory findings of Weston (1963) and Thiery et al. (1982) are not yet clear, our results support the conclusions of Weston (1963) and suggest that trunk neural crest cells migrate within the somitic mesenchyme.

In a related series of experiments, Newgreen, Scheel \& Kastner (1986), examined the relationship between the notochord and neural crest cell migration. They co-cultured two neural tube explants with the notochords attached in a variety of orientations. They reported that when the neural tube and notochord explants were oriented perpendicular to the dorsal surface of the neural tube, a cell-free zone was established between the tissues in which no neural crest cells approached the notochord. A similar cell-free zone was observed when the two explants were separated by a great distance. Because the neural crest cells neither migrate toward nor transiently contact the notochord, they concluded that the notochord releases some factor which repels migrating neural crest cells. The differences in the results obtained by Newgreen et al. (1986) and those obtained by Thiery et al. (1982) may result from different techniques used to isolate neural tubes and notochords from the embryo. The former investigators isolated the neural tube and notochord explants enzymically whereas the latter used microsurgical techniques. Newgreen et al. (1986) suggest that the notochord may retain its repulsive properties during enzymic digestion, while microsurgical techniques may disrupt the environment lateral to the notochord, thus facilitating abnormal migration of neural crest cells into the notochordal region. Studies from this laboratory (Bronner-Fraser, 1986) suggest that neural crest cells in vivo avoid the region surrounding the notochord.

Within individual somites, there appear to be positional differences which may guide motoneurone processes and migrating neural crest cells. Keynes \& Stern (1984) have recently reported that motor and sensory axons grow only through the anterior portion of the somite. Neural tube and somite rotation experiments suggested that the position within the somite, and not the orientation of the axons was important in determining the axonal routes. Neural crest cells may follow similar cues to those that influence motoraxon growth through the sclerotome. Recent studies using monoclonal antibodies to stain neural crest cells suggest that neural crest cells may also migrate through the anterior sclerotome (Rickmann, Fawcett \& Keynes, 1985; Bronner-Fraser, 1986). These antibodies for identifying neural crest cells together with the in vitro assay used in the present study provide two independent assays that suggest that neural crest cells migrate through the somites. 
We would like to thank Dr Scott Fraser for his helpful comments on the manuscript. This work was supported by USPHS Grant HD-15527-01 and Basic Research Grant 1-896 from the March of Dimes.

\section{REFERENCES}

Bellairs, R. (1979). The mechanism of somite segmentation in the chick embryo. J. Embryol. exp. Morph. 51, 227-243.

Bellairs, R. \& Veini, M. (1980). An experimental analysis of somite segmentation in the chick embryo. J. Embryol. exp. Morph. 55, 93-108.

BronNER-Fraser, M. (1986). Analysis of the early stages of trunk neural crest migration in avian embryos using monoclonal antibody HNK-1. Devl Biol. 115, 44-55.

CoHen, A. M. (1977). Independent expression of the adrenergic phenotype by neural crest in vitro. Proc. natn. Acad. Sci., U.S.A. 74, 2899-2903.

DETWILER, S. R. (1934). An experimental study of spinal nerve segmentation in Amblystoma with reference to the plurisegmental contribution to the brachial plexus. J. exp. Zool. 67, 395-441.

DETWILER, S. R. (1937). Observations upon the migration of neural crest cells, and upon the development of the spinal ganglia and vertebral arches in Amblystoma. Am. J. Anat. 61, 63-94.

Hamburger, V. \& Hamilton, H. L. (1951). A series of normal stages in the development of the chick embryo. J. Morph. 88, 49-92.

Keynes, R. J. \& Stern, C. D. (1984). Segmentation in the vertebrate nervous system. Nature, Lond. 310, 786-789.

Newgreen, D. F., Scheel, M. \& Kastner, V. (1986). Anatomical and experimental studies on early morphogenesis of the avian perichordal region: Differential effect of notochordal chondroitinase-sensitive material on neural crest and sclerotome cells. Cell Tiss. Res. (in press).

RickMANN, M., FAwCETT, J. \& Keynes, R. (1985). The migration of neural crest cells and motor axons through the rostral part of the chick somite. J. Embryol. exp. Morph. 90, 437-455.

TOSNEY, K. (1978). The early migration of neural crest cells in the trunk region of the avian embryo: an electron microscopic study. Devl Biol. 62, 317-333.

Thiery, J. P., Duband, J. L. \& Delouvee, A. (1982). Pathways and mechanisms of avian trunk neural crest cell migration and localization. Devl Biol. 93, 324-343.

TuCKer, G. C., AOyAMA, H., LiPINSKi, M., TURz, T. \& Thiery, J. P. (1984). Identical reactivity of monoclonal antibodies HNK-1 and NC-1: conservation in vertebrates on cells derived from neural primordium and on some leukocytes. Cell Diff. 14, 223-230.

VINCENT, M. \& THIERY, J. P. (1984). A cell surface marker for neural crest and placodal cells: further evolution of the peripheral and central nervous system. Devl Biol. 103, 468-481.

WeSton, J. A. (1963). A radioautographic analysis of the migration and localization of trunk neural crest cells in the chick. Devl Biol. 6, 279-310. 
